\title{
PEMANFAATAN TANAMAN PENUTUP TANAH DALAM SISTEM USAHA TANI
}

\author{
Kristin a Erniyani \\ Fakultas Pertanian Universitas Fiores \\ kristinaerni@yahoo.co.id
}

\section{SUMMARY}

The Use of Land Cover Crop on Agricultural System.

An intensive agriculture activity, especially that done on dry land, will result in a decrease in productivity. The land will get easily eroted, slopy, sour and poor in nutrition. Sustainable agricultural development needs technologies of conservation of land and water. One of such technologies is the technology of vegetatif conservation. This refers to the planting of trees, bush, grass or land covering crops. The planting of land covering crops functions to : 1) minimize erotion; 2) minimize the growth of weeds; 3 ) change the micro climate and the land temperature; 4) to make sources of livestock food avaibte; 5) increase the land organism; 6) improve the physical and chemical nature of the land. The findings of some researches show that the land covering crops can minimize the speed of erotion $40 \%$, increase the land fertility by $30 \%$ and minimize the growth of weeds by $50 \%$.

Keywords: cover crop, dry land, vegetatif conservation.

\section{PENDAHULUAN}

Pertanian berkelanjutan didefinisikan sebagai pengelolaan sumber daya alam untuk usaha pertanian guna membantu kebutuhan manusiayang terus bertambah sekaligus mempertahankan atau meningkatkan kualitas lingkungan dan melestarikan sumber daya alam (Reijntjes, et al, 1999). Sistem usaha tani yang berkelanjutan dapat diukur berdasarkan keuntungan yang diperoleh petani dan resiko yang mungkin terjadi dapat ditekan seminimal mungkin (Sutanto, 2002).

Usaha pertanian yang intensif terutama pada usaha pertanian lahan kering menimbulkan masalah penurunan produktivitas lahan. Santosa dkk., (2004) menyebutkan bahwa penyebab terjadinya penurunan produktivitas lahan tersebut antara lain tanahnya peka terhadap erosi, beriereng, tanah masam dan miskin unsur-unsurhara. Sumber air untuk pertanian lahan kering hanya berasal dari hujan dan embun. Umumnya pada lahan kering memiliki jumlah hujan tinggi dengan intensitas curah hujan rendah. Keadaan ini akan memicu terjadinya erosi terutama pada lahan beriereng \{Ábdurachman dan Sutono, 2002 dalam Dariah efa/,2004).

Pembangunan sistem pertanian berkelanjutan metnmtut untuk mengelola lahan dengan menerapkan teknologi konservasi tanah dan air. Upaya konservasi di lahan pertanian bukan saja pada usaha mengurangi erosi atau aliran permukaan, namun termasuk mempertahankan kesuburan tanah (Santosa dkk., 2004) untuk mempertahankan produktivitas perlanian yang berkelanjutan.
Salah satu teknologi konservasi tanah dan air adalah dengan teknik konservasi secara vegetatif atau pengelolaan tanah secara vegetatif. Pengelolan tanah secara vegetatif dapat berupa penanaman tamanan (pohon, semak, rumput) atau penanaman tanaman penutup tanah (cover crop).

Pengelolaan tanah secara vegetasi menjamin keberlangsungan keberadaan tanah dan air karena sifatnya : 1) menjamin kestabilan struktur tanah melalui sistem perakaran dengan memperbesar granulasi tanah; 2) penutupan lahan oleh tanaman penutup tanah dapat mengurangi evaporasi; 3) meningkatkan aktivitas mikroorganisme yang mengakibatkan peningkatan porositas tanah, sehingga memperbesar jumlah infiltrasi dan mencegah terjadinya erosi (Suhardi, 2003).

Tujuan pemanfaatan tanaman penutup tanah adalah mempertahankan kesuburan tanah pada ;usaha pertanian lahan kering.

\section{ULASAN}

\section{Kriteria dan Jenis Penutup Tanah}

Santosa dkk., (2004) menyatakan tanaman penutup tanah memiliki syarat : mudah diperbanyak terutama dengan biji, tumbuh cepat dan menghasilkan banyak daun, toleran terhadap pemangkasan dan injakan. Syarat lain adalah tidak menjadi tanaman inang bagi hama dan penyakit tertentu, sistem perakaran tidak berkompetisi dengan tanaman pokok, mampu menekan gulma.

Ochoa dan Oryarzun (2008) menyebutkan umumnya tanaman penutup tanah dibagi menjadi tiga kelompok, yaitu tanaman penutup tanah 
tinggi, semak dan pendek. Tanaman penutup tanah rendah seperti Centrosema pubescens
Pueraria javanica, Colopogonium, Mucuna prurien, Arachispintoi, daun pegagan.

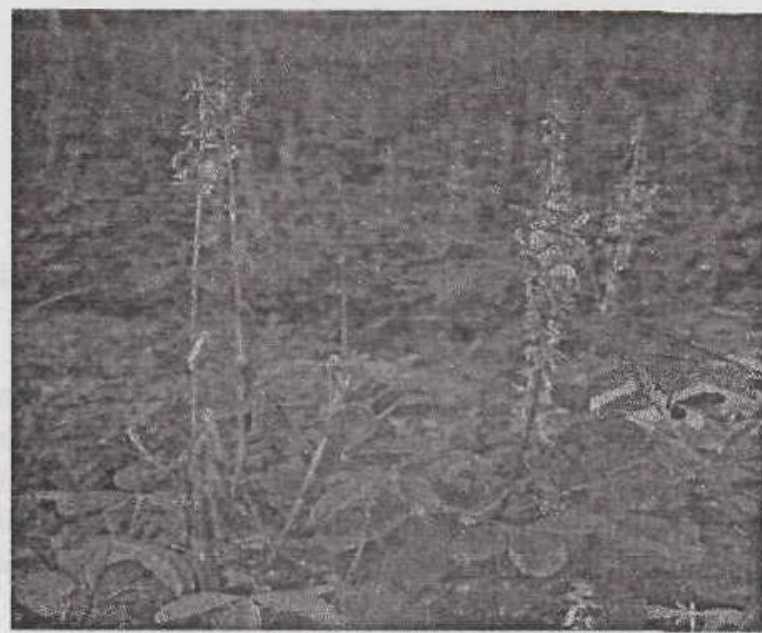

Gambar I. Crotalaria anagyroidcs

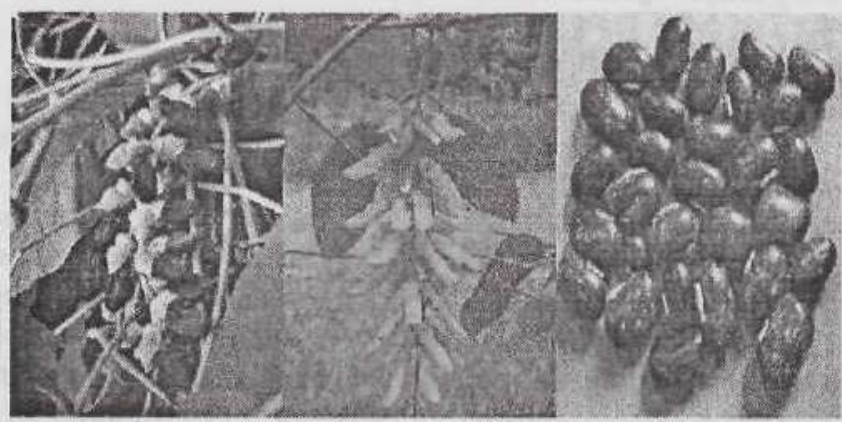

Gambar 3. Arachis pintoi di lantai kebun kopi

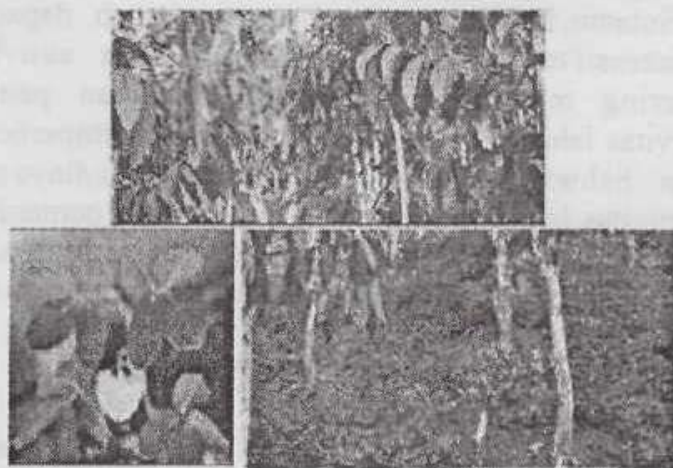

Gambar 3. Arachis pintoi di lantai kebun kopi

\section{Peran Leguminosa Sebagai Penutup Tanah}

Pada umumnya tanaman penutup tanah (cover crop) memiliki peran sebagai berikut: 1) dapat melindungi tanaman dari erosi percikan akibat jatuhnya tetasan air hujan, 2) menekan pertumbuhan gulma, 3) mengubah iklim mikro dan suhu tanah, 4) sebagai sumber pakan bagi ternak. Hasil pangkusan Arachis pintoi seluas 1 ha kebun lada dapat digunakan untuk memelihara ternak kambing sebanyak 5-10 ekor (BPTP Lampung, 5) meningkatkan aktivitas organisme tanah. 6) meningkatkan kandungan bahan organik tanah dan memperbaiki sifat fisik dan kimia tanah. Salah satu usaha menambah bahan organik dalam tanah adalah dengan menanam tanaman penutup tanah (Anom, 2008)

Tanaman leguminosa memiliki kemampuan untuk memfiksasi nitrogen dari udara. ICerja ini didukung oleh keberadaan 
bakteri rhizobium yang bersimbiosis dengan akar legum. Bakteri ini juga berpotensi dalam menjaga kesehatan tanah. Secara umum rizosfer ekosistem tanah yang sehat akan dihuni oleh organisme yang menguntungkan yang memanfaatkan substrat organik dari bahan organik atau eksudat tanaman sebagai sumber energi dan nutrisi (Hindersah dan Simarmata, 2004).

Rhizobium yang berasosiasi dengan tanaman legum mampu memfiksasi $100-300 \mathrm{~kg}$ N/ha dalam satu musim tanam dan meninggalkan sejumlah $\mathrm{N}$ untuk tanaman berikutnya. Rhizobium mampu mencukupi $80 \%$ kebutuhan nitrogen tanaman iegum dan meningkatkan produksi antara $10-25 \%$ (Susanto, 2002).

Tanaman penutup tanah jenis Mucuna $s p$ mampu tumbuh dengan baik pada kondisi tanam asam ( $\mathrm{pH}$ 5) sampai basa ( $\mathrm{pH}$ 8), dengan kondisi tanah yang miskin hara tanaman ini mampu menghasilkan bahan organik dari sisa-sisa tanaman sebesar 1,75 ton/ha (Kurnia et at, 1998 dalam Setiawan, 2008). Menurut penelitian yang dilakukan FAO (1990) dalam Setiawan (2008), selama kurun waktu satu tahun mukuna dapat menghasilkan 35 ton/ha dan dapat menggantikan $150 \mathrm{~kg}$ nitrogen ke dalam tanah.

Dalam memperbaiki sifat kimia tanah, selain menyumbangkan $\mathrm{N}$ bagi tanah melalui proses fiksasi nitrogen dan pada tanaman penutup Eanah legum jenis pohon dapat berperan sebagai penjaring hara. Hasil penelitian Suprayogo dkk., (2000) dalam Hairiah dkk., (2000) dalam mengukur $\mathrm{N}$ tercuci didapat bahwa pada kedalaman $0,80 \mathrm{~m}$ sampai $>0,80 \mathrm{~m}$ konsentrasi $\mathrm{N}$ minera! tertinggi pada tanaman monokultur jagung dibandingkan dengan campuran petai dan gamal.

Biomasa tanaman benguk (Mucuna sp) mampu menyumbangkan hara sebesar $23,2 \mathrm{~kg} \mathrm{~N}$; $2,0 \mathrm{~kg} \mathrm{P}$; dan 19,7 kg $\mathrm{K}$ dalam setiap ton bahan kering (Adiningsih dan Mulyadi, 1993). BPTP Lampung (__ mendapatkan penanaman Arachispintoi, dapat menghemat biaya pemupukan rata-rata $50 \%$ pertahun, karena tanaman ini dapat memberikan sumbangan bahan organik bagi tanaman lada dalam bentuk serasah dan menghemat biaya peny iangan lebih kurang $50 \%$.

Dari hasil penelitian Talaohu et al, (1994 dalam Setiawan, 2008) menyatakan bahwa penanaman mukuna bisa memperbaiki sifat kimia tanah yaitu:

1, Meningkatkan nilai $\mathrm{pH}$ tanah dari 4,2 menjadi 4,5. Pada umumnya unsur hara mudah diserap akar tanaman pada $\mathrm{pH}$ netral. Dengan kondisi $\mathrm{pH}$ tanah yang rendah unsur $\mathrm{P}$ tidak dapat diserap tanaman karena difiksasi oleh $\mathrm{Al}$ sehingga kadar $\mathrm{pH}$ tanah perlu dinaikkan agar unsur-unsur hara seperti $\mathrm{P}$ mudah diserap tanaman.

2. Meningkatkan C-organik dari $1,48 \%$ menjadi 1,83\%. Kandungan C-organik meningkat disebabkan oleh dekomposisi biomassa tanaman menjadi bahan organik. Semakin tinggi kandungan bahan organik tanah akan semakin mudah bagi tanaman untuk menyerap unsur hara.

3. Meningkatkan K-tersedia dari 0,07 me/100 gr menjadi 0,14 me/100 gr. Unsur K (kalium) merupakan unsur makro tanaman yang berfungsi sebagai pengatur pernafasan dan penguapan melalui pembukaan stomata, mempengaruhi proses fisiologis dan metabolik dalam sel. Unsur K diperlukan dalam proses fisiologis tanaman dan proses metabolisme dalam sel, mengatur pernafasan dan penguapan, meningkatkan daya tahan pada serangan hama dan kekeringan serta untuk menunjang perkembangan akar.

4. Meningkatkan KTK dari 4,92 menjadi 5,19 me/100 gr. Kapasitas Tukar Kation (KTK) merupakan sifat kimia yang sangat erat hubungannya dengan kesuburan tanah. Tanah dengan KTK tinggi mampu menyerap dan menyediakan unsur hara lebih baik dari pada tanah dengan KTK rendah. Karena unsur-unsur hara terdapat dalam kompleks serapan koloid maka unsur-unsur hara tersebut tidak mudah hilang tercuci oleh air.

Sisa-sisa tanaman penutup tanah akan menghambat kecepatan aliran permukaan (run off), oleh karena dapat mengurangi tekanan gesekan dan kapasitas pengaliran air dipermukaan tanah (Arinong,____ Penyisipan tanaman kacang-kacanagan penutup tanah Dolicos lab-lab efektif menekan erosi hingga $40 \%$ namun cenderung menurunkan hasil ubi jalar sebesar $3 \%$ (Suprayogo et at, 1997). Benguk mempunyai kemampuan menutup tanah dalam waktu yang relatif singkat yaitu 140 hari dapat menutup tanah 90\% (FAO, 1990 dalam Setiawan, 2008). Hal mi menunjukkan semakin cepat mengurangi erosi akibat aliran permukaan.

Irianto et al 1993 dan Sudharto et al., 1993 mengemukakan bahwa benguk dapat menyuburkan tanah, meningkatkan produktivitas tanah, meningkatkan hasil tanaman, dan menekan pertumbuhan alang-alang, tergantung pada cara mengolahan tanah. Efendi et at., (2001), penanaman benguk selama 3 bulan meningkatkan pori aerasi, pori air tersedia, indeks stabilitas agregat dan menurunkan kepadatan tanah LJltisoldi Jambi.

Hasil penelitian Elizal (2006) menunjukkan bahwa (I) Penutupan tanah di 
kebun vanili menggunakan LCC Arachis pintoi, mulsa segar Arachis pintoi, dan rumput alami meningkatkan pertumbuhan tanaman vanili muda yang ditunjukkan oleh peubah pertambahan panjang tanaman, pertambahan jumlah daun, diameter batang, dan Iuas daun dibandingkan dengan tanpa penutup tanah.

Petani di lembah Ekuador menanam tanaman penutup tanah (dua jenis mukuna, lablab, dan Canavalia ensiformis) dan pupuk hijau selama dua tahun, ada lapisan tanah bam yang dibentuk oleh bahan organik yang terurai perubahan warna tanah menjadi lebih gelap. Kelembaban tanah meningkat dan kandungaii hara tanah (nitrogen) meningkat sampai $35 \%$ (Ochoa dan Oyarzun, 2008).

Penggunaan tanaman penutup tanah dan pupuk hijau akan menyediakan lingkungan yang aman bagi organisme tanah. Di Ekuador, pada lahan kering dengan curah hujan rendah dilaporkan bahwa terjadi peningkatan popuiasi cacing tanah dan mikroorganisme perombak lainnya (Ochoa dan Oyarzun, 2008). Sudharto dkk., (1993) pada penelitian di Jambi mendapatkan bahwa penutup tanah dengan legum dapat memperbaiki media tumbuh mikroba dalam tanah, misalnya azotobakter dan jamur.

\section{SIMPULAN}

Penggunaan tanaman penutup tanah dapat menurunkan laju erosi sampai $40 \%$, meningkatkan kesuburan tanah sampai $30 \%$ dan menekan pertumbuhan gulma sampai $50 \%$.

\section{DAFTAR PUSTAKA}

Anom. 2008 Enam Upaya Mempertahankan Kualitas Kesuburan Tanah. http:// warungpupuk.com/?p=10.diakses tanggal21Mei2009

BPTP Lampung.___Arachis Pintoi Sebagai Tanaman Penutup Tanah Pada Perkebunan Lada.

Dariah, A., A. Rachman, dan U. Kurnia. 2004. Erosi dan Degradasi Lahan Kering di Indonesia. Dalam: Teknologi Konservasi Tanah Pada Lahan Kering Berlereng. Pusat Penelitian dan Pengembangan Tanah dan Agroklimat. Badan Penelitian dan
Pengembangan Pertanian. Depertemen Pertanian.

Evizal, R. 2006. Pengaruh Penutup Tanah Dan Letak Aplikasi Pupuk Kandang Terhadap Pertumbuhan Vanili. Laporan Hasil Penelitian. Fakultas Pertanian. Uni versitas Lampung. h t t p : / / d i g i l i b. i t b.a c. $\mathrm{id} / \mathrm{gdl}$.php?mod=browse \&op=read\&id -laptunilapp-gdl-res-2006-rusdievriz116

Hairiah, K, S.R. Utami, D. Suprayogo, Widianto, SM Sitompul, B Lusiana, R Mulia, M van Noordwijk, G Cadisch. 2000. Agroforestri pada tanah Masam di daerah Tropika Basah : pengelolaan interaksi antara pohon-tanah-tanaman semusim. ICRAF

Hindersah, R dan T. Simarmata. 2004. Potensi Rhizobakteri Azotobacter dalam Meningkatkan Kesehatan Tanah. J. Natur Indonesia. 5 (2): 127-133

Ochoa, M., Pedro J. Oyarzun. 2008. Tanaman Penutup Tanah yang Serba Bisa. Salam. 24Juni.

Reijntjes C, Haverkort B, Waters-Bayers A. 1999. Pertanian Masa Depart. Diterjemahkan oleh Y. Sukoco. Yogyakarta: Kanisius.

Santosa, D.. J. Purnomo, I G P Wigena, dan E. Tuherkih. 2004. Teknologi Konservasi Tanah Vegetatif. Dalam: Teknologi Konservasi Tanah Pada Lahan Kering Berlereng. Pusat Penelitian dan Pengembangan Tanah dan Agroklimat. Badan Penelitian dan Pengembangan Pertanian. Depertemen Pertanian.

Setiawan, H. 2008. Pemanfaatan Tanaman Mukuna Dalam Rehabilitasi Lahan Terdegradasi.http://balithutmakassar.or jd/index.php?option^com_content\&ta sk=view\&id=57\&Itemid $=\overline{5} 3$

Suhardi. 2003. Efektivitas Vegetatif Dalam -j Konservasi Tanah Dan Air Pada Suatu DAS. http://tumoutou.net/704 07134/ suhardi.pdf

Susanto, R. 2002. Penerapan Pertanian Organik. Kanisius Yogyakarta 